\title{
Kajian Lahan Potensial untuk Budidaya Perikanan dari Citra Satelit di Pantai Timur Belitung
}

\section{Jonson Lumban-Gaol, NyomanMetta N. Natih, MarlisYulianto}

Institut Pertanian Bogor, Indonesia

Email Koresponden: jonson_lumbangaol@yahoo.com

Diterima: Februari 2018 /Refisi: Maret 2018 Disetujui: 19 September 2018

(c) 2018 Fakultas Geografi UGM dan Ikatan Geograf Indonesia (IGI)

\begin{abstract}
Abstrak Pemetaan lahan yang potensial untuk budidaya perikanan dilakukan melalui pemetaan topografi dan tutupan lahan dari citra satelit serta survei lapang di perairan pantai Timur Belitung. Peta Topografi estimasi dari citra satelit mempunyai pola yang sama dengan hasil pengukuran terestris dimana ketinggian lahan semakin meningkat mulai dari garis pantai menuju daratan. Data hasil pengukuran topografi secara terestris lebih tinggi dari data topografi estimasi dari data satelit. Tipe pasut di perairan pantai Belitung timur adalah tipe tunggal. Data pasut ini digunakan menjadi acuan untuk pengukuran topografi secara terestris. Peta tutupan lahan hasil intrepretasi dari citra satelit diklasifikasikan menjadi kelas: hutan primer, hutan sekunder, belukar, rawa/air, lahan terbuka, permukiman dan galian tambang. Berdasarkan peta topografi, peta tutupan lahan dan data pasang surut maka lahan di wilayah kajian pesisir pantai Timur Belitung potensial dikembangkan untuk budidaya perikanan seluas 9.000 ha.
\end{abstract}

Kata kunci : budidaya, perikanan, satelit, penggunaan lahan, topografi

\begin{abstract}
Mapping potential land for aquaculture was done through topography and land cover mapping direved satellite imagery and field survey in the east coast of Belitung. Topographic data derived satellite and terrestrial measurement shows that topographic patterns increase as we move from the coastal line to inland. Topographic data from the terrestrial measurement was higher than satellite estimations. The type of tide in the east coast Belitung's is the diurnal type. Within this research, tidal data was used as a reference terrestrial topographic measurement. Land coverage maps from satellite images were classified into primary and secondary forests, grove forests, marsh/water lands, open land, inhabited land and mining areas. According to topographic, land cover map, and tide pattern it can be confirmed that the eastern coastal area of Belitung has potential to be developed into an aquaculture fishery area of 9,000 ha.
\end{abstract}

Keywords: aquaculture, fishery, satelitte, land cover, topography

\section{PENDAHULUAN}

Indonesia sebagai negara kepulauan memiliki garis pantai sekitar $90.000 \mathrm{~km}$. Namun secara spasial tidak semua wilayah pantai dapat dimanfaatkan untuk budidaya perikanan. Beberapa faktor harus dipertimbangkan untuk penentuan lahan budidaya perikanan seperti faktor lingkungan fisik, kimia dan biologi. Bererapa faktor yang perlu dikaji untuk pengembangan lahan budidaya perikanan perlu dikaji kelerengan lahan, jenis dan tekstur tanah, tutupan lahan dan drainase, suhu perairan, kecerahan dan pola amplitudo pasang surut air laut, oksigen terlarut, amoniak, salinitas, $\mathrm{pH}$ dan $\mathrm{H}_{2} \mathrm{~S}$, curah hujan dan hari hujan (Ross, et al., 1993; DKP, 2002).

Ketersedian data spasial menjadi sangat penting sebagai dasar untuk mengkaji kesesuaian lahan untuk kegiatan budidaya perikanan. Namun demikian ketersediaan data spasial skala detail khususnya untuk wilayah pantai masih sangat minim di Indonesia. Keterbatasan data spasial saat ini dapat diatasi dengan teknologi penginderaan jauh (remote sensing) satelit karena teknologi ini cukup efektif untuk penyediaan data spasial di wilayah pesisir dan laut (Setiawan et al., 2014, Wahidin et al., 2015).
Teknologi penginderaan jauh (inderaja) satelit mempunyai kelebihan dan juga keterbatasan. Teknologi inderaja mampu meliput wilayah yang luas dalam waktu yang bersamaan (sinoptik). Namun ketelitian data hasil estimasi dari sensor satelit secara umum lebih rendah dibandingkan dengan data pengukuran langsung di lapangan. Untuk meningkatkan akurasi data dari citra satelit maka diupayakan pengembangan resolusi spasial dan spektral sensor satelit. Berbagai sensor satelit mulai dari resolusi spasial menengah hingga tinggi seperti Land satelit (Landsat) dan Satellites Pour l'Observation de la Terre (SPOT) telah dimanfaatkan untuk pemetaan penutupan lahan dan habitat perairan dangkal (Berlanga-Robles and Ruiz-Luna, 2002, Lumban-Gaol et al., 2007, 2014, Shalaby and Tateishi, 2007, Jhonnerie et al., 2015).

Dari berbagai penelitian yang telah dilakukan, akurasi klasifikasi tutupan lahan dari data satelit cukup tinggi yakni lebih besar dari 70 \% (Foody, 2002, Manandhar et al., 2009). Estimasi ketinggian lahan dari citra satelit cukup akurat (Miliaresis and Paraschou, 2005). Hubungan antara elevasi hasil estimasi dari sensor satelit SRTM dengan pengukuran dari GPS di wilayah Phuket dan Catskill cukup tinggi dengan 
koefisien determinasi $\left(\mathrm{R}^{2}\right)$ mencapai 0.97 hingga 0.99 (Gorocovick and Voustianiouk, 2006).

Peta topografi yang dihasilkan dari pengolahan citra SRTM dibandingkan dengan konturyang dihasilkan dari Peta RBI skala 1:25.000, tidak memberikan perbedaan yang signifikan, dan masih masuk dalam toleransi jika digunakan untuk perencanaan. Namun untuk peta teknis (skala besar), hasil pengukuran teresteris masih yang terbaik.

Provinsi Kepulauan Bangka Belitung dengan luas perairan laut $65.301 \mathrm{~km}^{2}$, panjang garis pantai $1.200 \mathrm{~km}$ mempunyai potensi areal budidaya air laut 120.000 ha dengan potensi produksi 1.216.000 ton/tahun. Namun demikian menurut data tahun 2015, produksi budidaya ikan dari daerah ini masih dibawah 10.000 ton/tahun. Oleh karena itu masih terbuka peluang pengembangan usaha budidaya perikanan di wilayah ini.

Tahap awal yang sangat penting untuk keberhasilan usaha budidaya perikanan adalah pemilihan lokasi budidaya ikan. Beberapa informasi penting yang dibutuhkan untuk pemilihan lokasi budidaya ikan adalah peta penutupan lahan dan peta topografi lahan. Peta penutupan lahan menjadi salah satu petunjukan untuk menentukan lahan yang paling mudah diolah untuk budidaya perikanan. Peta topografi membantu penentukan kokasi budidaya perikanan berdasarkan kontur lahan. Lahan dengan kontur yang relatif datar akan mempermudah pengerjaan pembuatan tambak sehingga dapat menghemat biaya. Informasi dari peta topografi lahan juga diperlukan untuk menghitung volume tanah yang akan digali/timbun untuk membuat kolam. Peta topografi juga dapat digunakan sebagai dasar untuk menentukan saluran masuk dan keluar air.

Metoda konvensional untuk pemetaan topografi adalah dengan pengukuran terestris. Pemetaan untuk areal yang luas memerlukan waktu yang cukup lama dan peralatan yang banyak dan akan berakibat kepada tingginya biaya pemetaan lahan. Oleh karena itu pemetaan topografi dan penutupan lahan dengan menggunakan citra satelit perlu dikaji khususnya di pantai Timur Belitung. Tujuan penelitian ini adalah untuk membuat peta topografi dan tutupan lahan di area rencana pembuatan budidaya perikanan serta pengukuran tinggi pasut di sekitar pantai sebagai dasar untuk perencanaan lokasi budidaya perikanan pantai.

\section{METODE PENELITIAN}

Kegiatan utama dalam penelitian ini adalah pengolahan citra satelit dan survei lapang. Survei lapang dilakukan untuk pengukuran topografi dan pengukuran pasang surut di dua titik pengamatan selama 30 hari di pantai Timur Pulau Belitung Kabupaten Belitung Provinsi Bangka Belitung (Gambar 1).

Data yang dikumpulkan adalah: (1) Citra satelit ASTER full band dan Citra SRTM untuk area studi, (2) Data ketinggian lahan dari pengukuran dengan theodolith dan data pasang surut dari pengamatan papan pasut (Gambar 1).

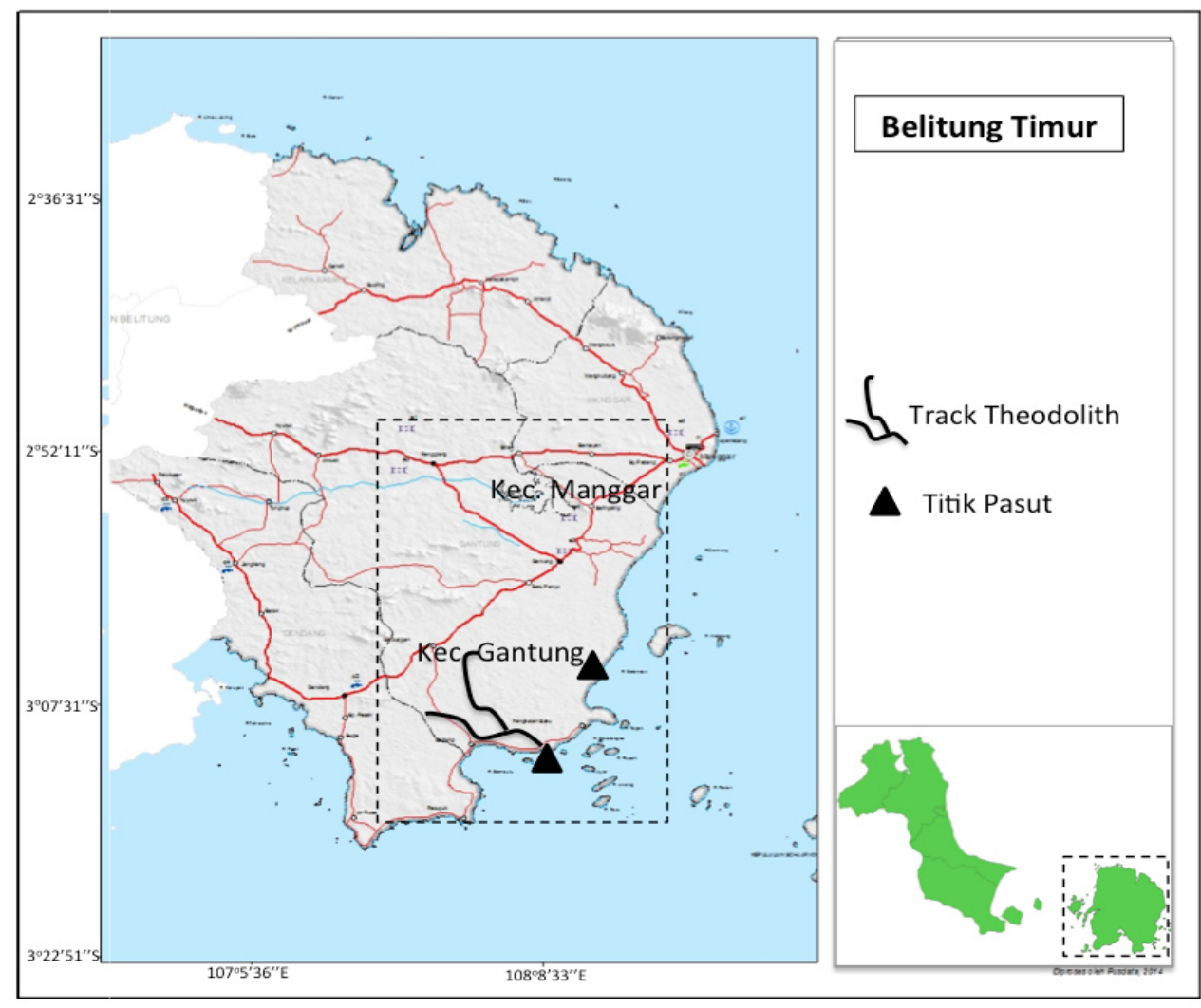

Gambar 1. Lokasi pengukuran dengan Theodolit dan stasiun pengukuran pasut. 


\section{Pengolahan Citra Satelit}

Pengolahan awal citra meliputi dimulai dengan koreksi atmosferik dan koreksi geometri. Penajaman Citra (Image Enhancement), dilakukan dengan menggunakan citra komposit warna semu dengan mengkombinasi tiga saluran data masing-masing sebagai warna merah (R), hijau (G) dan biru (B). Selanjutnya dilakukan klasifikasi penutupan lahan dengan metode maksimun likelihood dengan supervised classification.

Pembuatan kontur ketinggian dilakukan dengan teknik contouring pada citra satelit menggunakan fasilitas yang telah tersedia pada perangkat lunak pengolah citra. Selanjutnya dilakukan overlay hasil conturing. Hasil klasifikasi citra dan delianiasi batas objek dibuat menjadi peta kerja yang digunakan pada kegiatan survei lapangan.

Kegiatan setelah survei lapang adalah perbaikan hasil interpretasi citra satelit untuk pembuatan peta penutupan lahan dan peta. Proses editing dan revisi ini dilakukan secara full digital menggunakan perangkat lunak Sistem Informasi Geografis (SIG). Peta yang dihasilkan disusun dalam bentuk lembaran peta. Proses kartografi mengacu pada model kartografi peta topografi yang dikeluarkan BIG. Proses kartografi pada peta-peta yang dihasilkan pada skala cetak 1:25.000.

\section{Pengukuran Topografi dan Tinggi Pasang Surut}

Pengukuran topografi dilakukan dengan peralatan Theodolith. Jumlah stasiun titik pengukuran adalah sebanyak 84 titik yang dimulai dari garis pantai menuju ke arah daratan (Gambar 1).

Pengukuran pasang surut dilakukan pada dua lokasi, yaitu di Gosong Cina (03 04'46.9"LS, $108^{\circ} 12^{\prime} 20.8^{\prime \prime}$ BT) dan di Batu Putih (0309'37.9”LS, $108^{\circ} 10^{\prime} 12.3^{\prime \prime B T)}$ (Gambar 1). Pengukuran dilakukan dengan cara memasang papan Pasut pada kedalaman tetentu.Pengukuran pasang surut dilakukan setiap 60 menit dengan lama pengukuran selama 30 hari.

Data hasil pengukuran pasut selama 30 hari dengan interval 60 menit digunakan sebagai input data untuk menghitung komponen pasut yakni M2, S2, K1, O1, N2. Untuk mendapatkan konstanta pasut digunakan metode standar yaitu Metode Admiralty.

Dari analisis ini juga akan dihasilkan posisi-posisi/ elevasi muka laut rerata $(\mathrm{MSL}=$ Mean Sea Level), muka laut tinggi tertinggi $(\mathrm{HHWL}=$ High highest Water Level), muka laut rerata tertinggi $(\mathrm{MHWL}=$ Mean High Water Level), muka laut rerata terendah $(\mathrm{MLWL}=$ Mean Low Water Level), muka laut surut terendah (LLWL= Low Lowest Water Level), tipe dan kisaran pasang surut yang terjadi di lokasi pengukuran.

Secara kuantitatif, tipe dari pasang surut pada suatu perairan dapat ditentukan oleh perbandingan (nisbah) antara amplitudo (tinggi gelombang) unsurunsur pasut tunggal utama dengan amplitudo unsur- unsur pasut ganda utama. Nisbah ini dikenal sebagai bilangan Formzahl yang mempunyai formula sebagai berikut:

$$
\mathrm{F}=(\mathrm{O} 1+\mathrm{K} 1) /(\mathrm{M} 2+\mathrm{S} 2)
$$

Keterangan :

F : bilangan Formzahl.

O1 : amplitudo komponen pasut tunggal utama yang disebabkan oleh gaya tarik bulan.

K1 : amplitudo komponen pasut tunggal yang disebabkan oleh gaya tarik bulan dan surya.

M2 : amplitudo komponen pasut ganda utama yang disebabkan oleh gaya tarik bulan.

S2 : amplitudo komponen pasut ganda utama yang disebabkan oleh gaya tarik surya.

Dengan demikian jika nilai $\mathrm{F}$ berada antara :

$<0.25 \quad$ : pasut bertipe ganda.

$0.26-1.50$ : pasut bertipe campuran dengan tipe ganda yang menonjol.

$1.51-3.00$ : pasut bertipe campuran dengan tipe tunggal yang menonjol.

$>3.00 \quad$ : pasut bertipe tunggal.

\section{HASIL DAN PEMBAHASAN}

\section{Tinggi Pasang Surut}

Grafik pasut di dua lokasi yakni di desa Gosong Cina dan di desa Lokasi Batu Putih tertera pada Gambar 2. Lokasi Benchmark (BM) tertera pada Gambar 3. Dari data pasut pengukuran dan perhitungan diperoleh nilai bilangan Formzahl $(F)>3.0$ maka tipe pasut di perairan lokasi studi adalah tipe tunggal, yaitu terjadi satu kali pasang dan satu kali surut dalam waktu satu hari.

Kisaran pasut harian seperti tinggi muka laut maksimum/minimum ataupun tinggi rata-rata tertera pada Tabel 1. Perubahan tinggi muka laut di perairan sekitar Gosong Cina berkisar antara $55 \mathrm{~cm}$ hingga 220 $\mathrm{cm}$ dengan rata-rata $134 \mathrm{~cm}$, sedangkan di Batu Putih berkisar antara $45 \mathrm{~cm}$ hingga $212 \mathrm{~cm}$ dengan rata-rata $137 \mathrm{~cm}$. Kisaran pasut yang besar terjadi pada waktu bulan purnama atau bulan baru, yang disebut sebagai pasang purnama. Sebaliknya, kisaran pasut yang paling kecil terjadi pada saat bulan berada di perempat pertama dan perempat ketiga, dan dikenal sebagai pasang perbani.

Data pasut digunakan sebagai dasar untuk menganalisa areal lahan budidaya ikan yang bisa dialiri air secara alami dan juga untuk menentukan saluran air masuk dan keluar dari kolam budidaya. 


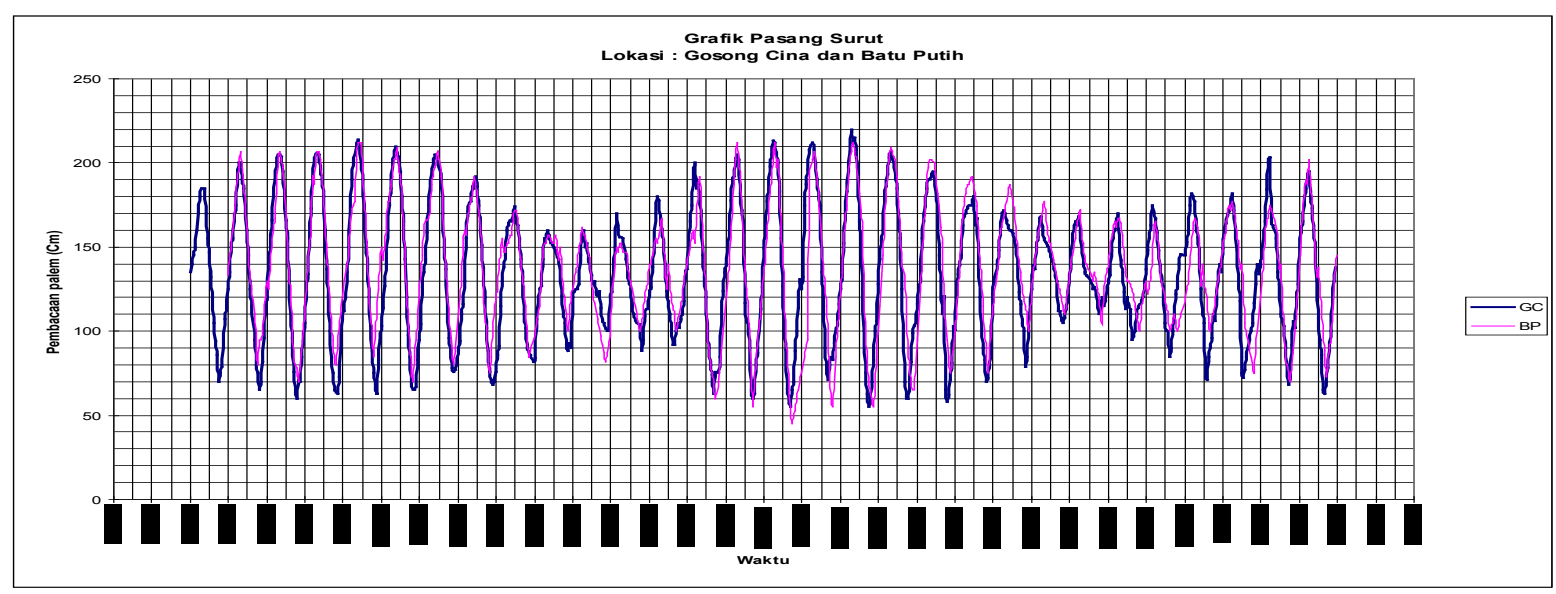

Gambar 2. Grafik pasang surut selama 30 hari di desa Gosong Cina dan Pasir Putih.

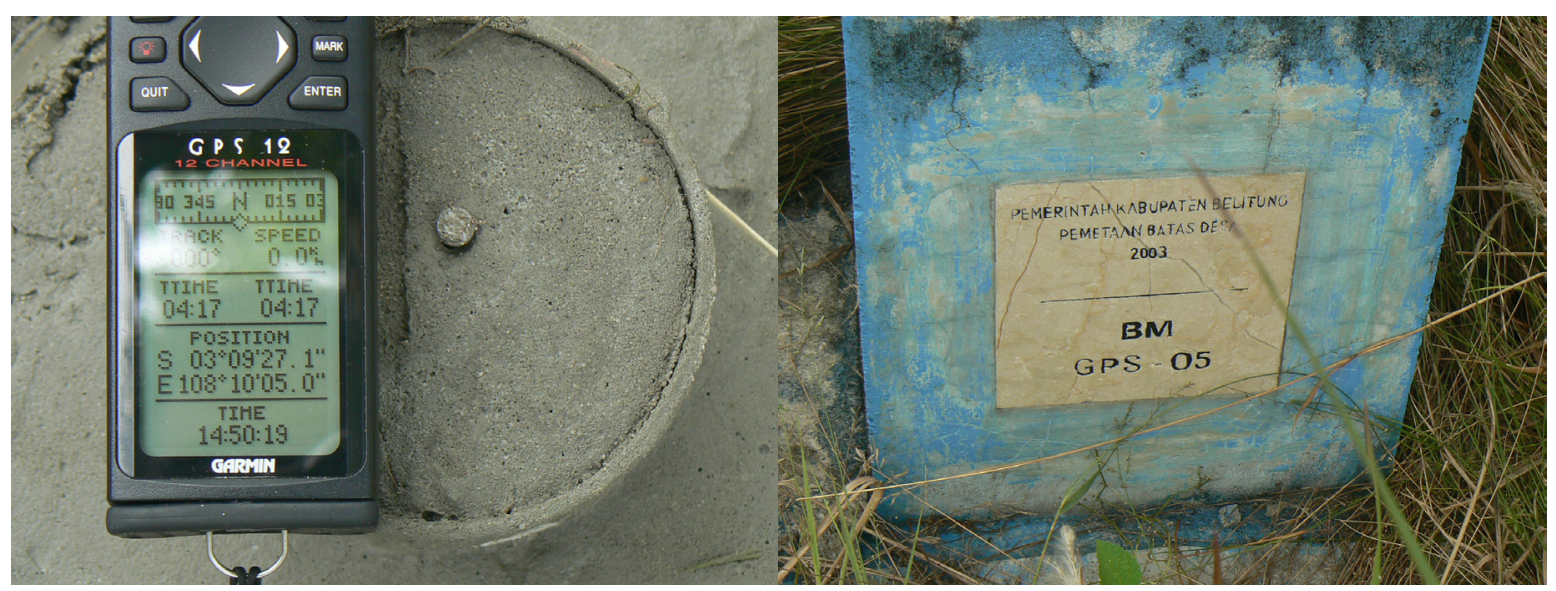

Gambar 3. Benchmark di desa Gosong Cina dan Batu Putih

Tabel 1. Data pengukuran tinggi muka laut selama 30 hari di Gosong Cina dan Batu Putih

\begin{tabular}{cllcc}
\hline No & Kisaran Muka Laut & Notasi & G. Cina $(\mathrm{cm})$ & BatuPutih $(\mathrm{cm})$ \\
\hline 1 & Tinggi muka laut maksimum & $(\mathrm{HHWL})$ & 220 & 212 \\
2 & Tinggi muka laut rata-rata pasang & $(\mathrm{HWL})$ & 210 & 200 \\
3 & Tinggi muka laut rata-rata & $(\mathrm{MSL})$ & 134 & 137 \\
4 & Tinggi muka laut rata-rata surut & $(\mathrm{LWL})$ & 60 & 70 \\
5 & Tinggi muka laut minimum & $(\mathrm{LLWL})$ & 55 & 45 \\
\hline
\end{tabular}

Sumber: Diolah dari hasil pengukuran pasut selama 30 hari

\section{Pemetaan Topografi}

Peta topografi estimasi dari satelit dibuat dalam peta skala 1:25.000 seperti tertera pada Gambar 4 . Rata-rata ketinggian hasil pengukuran secara terestris adalah sebesar 5,55 $\mathrm{m}$ dari titik BM sedangkan tinggi hasil estimasi citra satelit sebesar 4,96 m (Tabel 1). Data ini menunjukkan bahwa estimasi rata-rata ketinggian lahan dari citra lebih rendah dibandingkan dengan rata-rata ketinggian pengukuran secara terestris yakni sebesar $60 \mathrm{~cm}$.

Lebih dari 75 persen data pengukuran terestris secara konsisten lebih tinggi dibandingkan dengan data ketinggian estimasi dari citra satelit. Perbedaan ini bisa terjadi karena titik acuan pada citra dan pengukuran dengan teresteris berbeda. 
Jonson Lumban-Gaol/Majalah Geografi Indonesia Vol. 32, No.2, September 2018 : 207 - 215

\begin{tabular}{|c|c|c|c|c|c|}
\hline Stasiun & $\begin{array}{c}\text { Pengukuran Terestris } \\
(\mathrm{m})\end{array}$ & $\begin{array}{c}\text { Estimasi Citra } \\
(\mathrm{m})\end{array}$ & Stasiun & $\begin{array}{c}\text { Pengukuran Terestris } \\
(\mathrm{m})\end{array}$ & $\begin{array}{c}\text { Estimasi Citra } \\
(\mathrm{m})\end{array}$ \\
\hline BM. Z & 2,49 & 1,50 & 42 & 5,50 & 5,25 \\
\hline 1 & 2,66 & 2,00 & 43 & 5,32 & 5,25 \\
\hline 2 & 3,32 & 2,50 & 44 & 5,28 & 5,25 \\
\hline 3 & 4,65 & 3,25 & 45 & 4,64 & 5,00 \\
\hline 4 & 5,12 & 3,75 & 46 & 5,84 & 5,00 \\
\hline 4 & 5,48 & 4,25 & 47 & 6,24 & 5,00 \\
\hline 5 & 5,75 & 4,35 & 48 & 6,16 & 5,00 \\
\hline 6 & 5,58 & 4,75 & $\mathrm{BM} \mathrm{T}$ & 6,05 & 5,25 \\
\hline 7 & 5,32 & 5,25 & 1 & 5,45 & 5,00 \\
\hline 8 & 5,76 & 5,00 & $1 \mathrm{a}$ & 4,97 & 5,00 \\
\hline 9 & 5,62 & 5,25 & 2 & 4,52 & 4,75 \\
\hline 10 & 5,15 & 4,50 & 3 & 4,72 & 4,50 \\
\hline 11 & 4,91 & 5,00 & 4 & 4,86 & 4,00 \\
\hline 12 & 4,77 & 5,00 & 5 & 4,56 & 4,00 \\
\hline 13 & 4,64 & 5,00 & 6 & 5,23 & 4,00 \\
\hline 14 & 5,04 & 5,00 & 7 & 5,48 & 4,00 \\
\hline 15 & 5,55 & 5,00 & 8 & 5,93 & 4,25 \\
\hline 16 & 5,74 & 5,00 & 9 & 6,05 & 4,25 \\
\hline 17 & 4,74 & 5,00 & 10 & 5,92 & 4,00 \\
\hline 18 & 5,40 & 5,25 & 11 & 6,03 & 4,50 \\
\hline 19 & 5,31 & 5,50 & 12 & 6,05 & 4,25 \\
\hline 20 & 5,64 & 5,75 & 13 & 5,62 & 4,00 \\
\hline 21 & 5,90 & 5,75 & 14 & 5,81 & 4,00 \\
\hline 22 & 5,65 & 5,75 & 15 & 5,77 & 4,00 \\
\hline 23 & 5,77 & 5,75 & 16 & 5,77 & 4,00 \\
\hline 24 & 6,18 & 5,75 & 17 & 5,97 & 5,50 \\
\hline 25 & 5,99 & 5,75 & 18 & 4,97 & 4,50 \\
\hline 26 & 6,20 & 5,50 & 19 & 3,84 & 5,25 \\
\hline BM B & 6,28 & 5,00 & 20 & 4,21 & 5,75 \\
\hline 28 & 5,85 & 5,00 & 21 & 5,13 & 6,25 \\
\hline 29 & 6,09 & 5,00 & 22 & 5,77 & 6,50 \\
\hline 30 & 6,11 & 5,00 & 23 & 5,60 & 6,50 \\
\hline 31 & 6,16 & 5,00 & 24 & 6,38 & 6,50 \\
\hline 32 & 6,23 & 5,00 & 25 & 5,35 & 6,25 \\
\hline 33 & 6,19 & 5,25 & 26 & 5,56 & 6,25 \\
\hline 34 & 6,14 & 5,25 & 27 & 6,09 & 6,00 \\
\hline 35 & 6,17 & 5,25 & 28 & 7,04 & 5,50 \\
\hline 36 & 6,23 & 5,25 & 29 & 7,32 & 5,50 \\
\hline 37 & 6,23 & 5,25 & BM S & 6,45 & 5,25 \\
\hline 38 & 6,34 & 5,25 & 31 & 6,56 & 5,25 \\
\hline 39 & 6,05 & 5,25 & 32 & 5,96 & 5,50 \\
\hline 40 & 5,54 & 5,25 & 33 & 6,09 & 5,75 \\
\hline \multirow[t]{2}{*}{41} & 5,83 & 5,25 & 34 & 5,77 & 6,00 \\
\hline & Rata-rata & & & 5.55 & 4.96 \\
\hline
\end{tabular}

Sumber: Diolah dari hasil pengukuran di lapang

Peta Topografi estimasi dari citra satelit menunjukkan pola kontur yang mirip dengan kontur hasil pengukuran secara teresteris dengan Theodolith, dimana terlihat peningkatan ketinggian lahan dari pantai menuju daratan. Sebagai contoh, hasil estimasi ketinggian dari citra di titik BM adalah sekitar 2 meter dan semakin meningkat menuju wilayah darat hingga 5-6 meter (Gambar 4). 


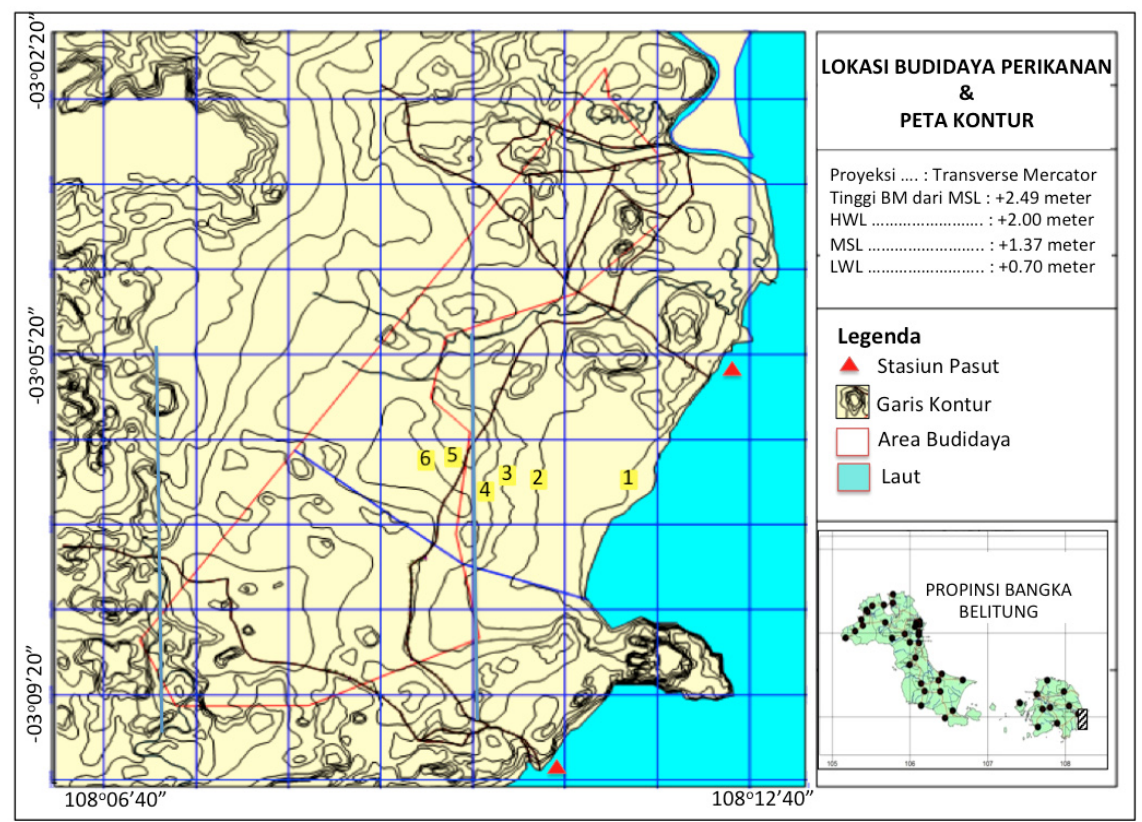

Gambar 4. Peta Kontur (topografi) skala 1:25.000 di Pantai Timur Belitung dengan.

Hasil estimasi ketinggian dari citra satelit dan pengukuran dengan Theodolith tidak menunjukkan perbedaan ketinggian di wilayah lahan terbuka, namun di wilayah dengan penutupan lahan hutan primer telihat perbedaan yang cukup tinggi. Hal ini bisa terjadi karena ketinggian yang terdeteksi oleh sensor satelit bukan ketinggian lahan tetapi kanopi pohon. Oleh karena itu ketinggian lahan yang berada di wilayah hutan produksi perlu dikoreksi dengan peta penutupan lahan untuk memberikan data yang akurat sebagai dasar studi perencanaan awal lokasi budidaya perikanan.

\section{Pemetaan Penutupan Lahan}

Peta penutupan lahan skala 1:25.000 berdasarkan hasil interpretasi dari citra satelit dan survei lapang tertera pada Gambar 5. Penutupan lahan di sekitar wilayah budidaya dapat dikelompokkan menjadi: (1) hutan primer, (2) hutan sekunder, (3) belukar, (4) rawa/ air, (5) lahan terbuka, (6) permukiman dan (7) galian tambang. Secara umum terlihat bahwa penutupan lahan di wilayah bagian selatan adalah hutan primer, di bagian tengah umumnya adalah belukar dan di bagian utara adalah bekas galian tambang atau tambang yang masih aktif. Di lokasi tambang timah atau bekas tambang umumnya terdapat timbunan tanah dengan ketinggian hingga 3 meter dari ketinggian sekitarnya. Di beberapa wilayah pinggir pantai terdapat vegetasi mangrove (Gambar 5). Beberapa jenis tanaman yang menutupi lahan di sekitar lokasi penelitian terteta pada Gambar 6.

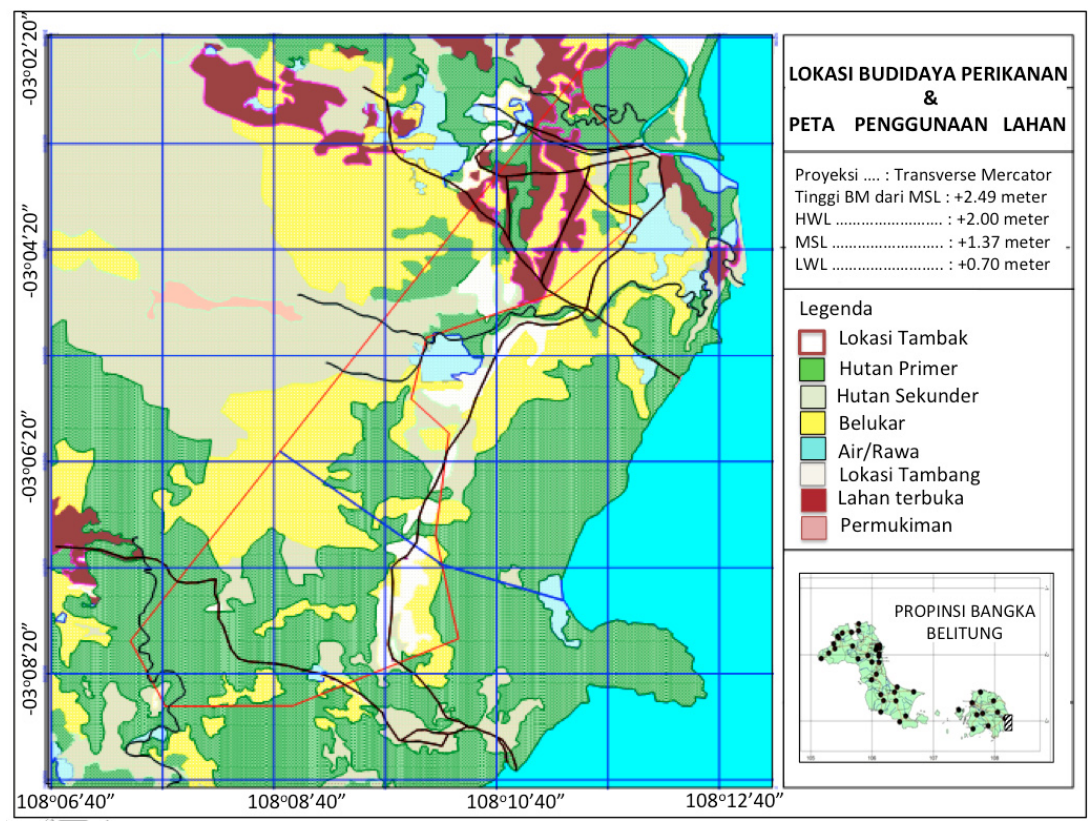

Gambar 5. Peta penutupan lahan skala 1:25.000 di pantai timur Belitung. 

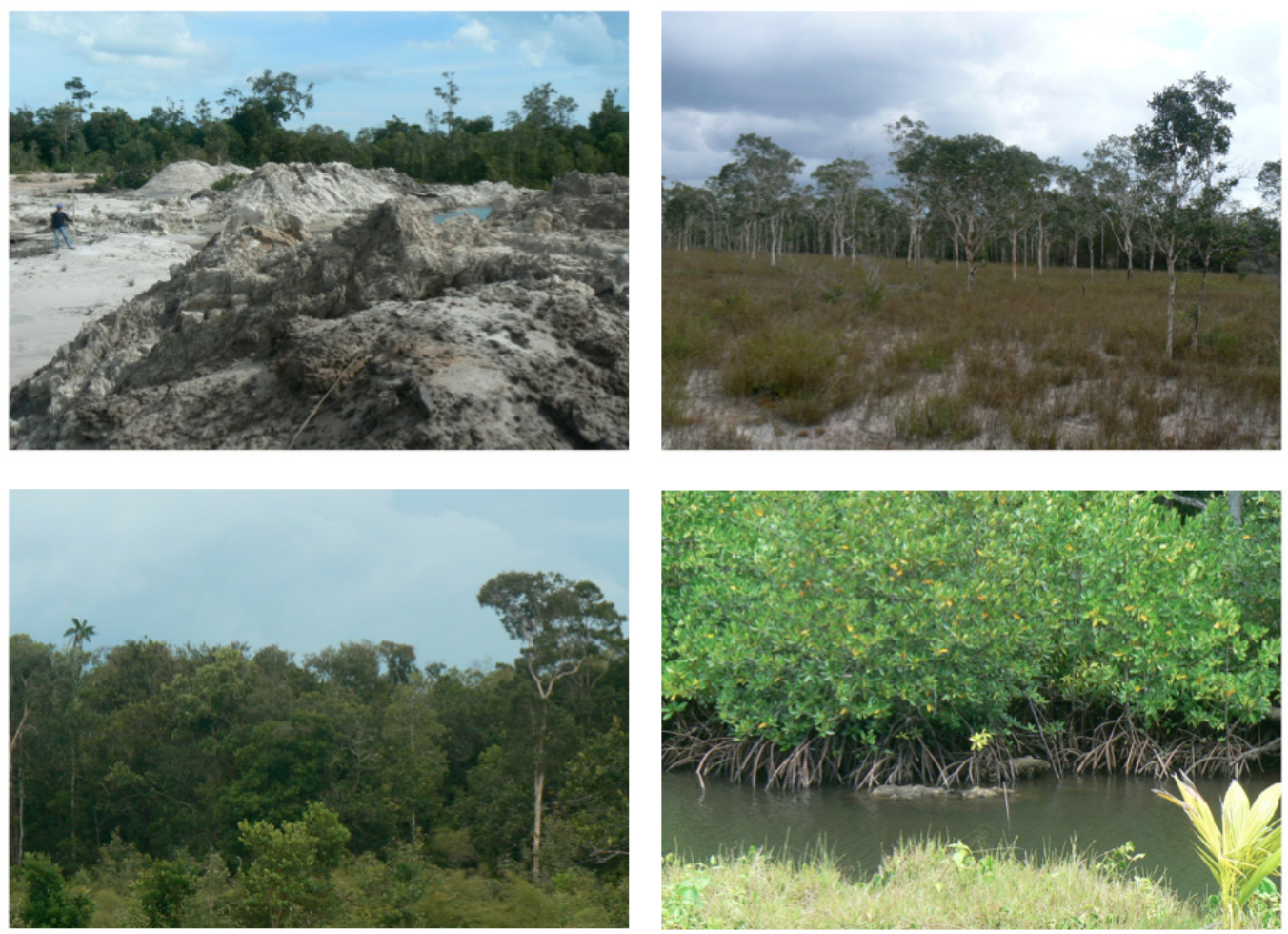

Gambar 6. Beberapa tutupan lahan di perairan pantai Belitung Timur.

\section{Lahan Potensial Budidaya Perikanan}

Berdasarkan karakteristik lingkungan pantai Timur Pulau Belitung seperti topografi, penutupan lahan pantai dan kondisi pasang surut maka luas lahan yang potensial untuk dimanfaatkan sebagai lahan budidaya adalah sekitar 9.000 ha seperti tertera pada Gambar 7. Lahan yang sesuai untuk kegiatan budidaya adalah areal dengan ketinggian lebih kecil dari 5-6 m dari tinggi muka laut rata-rata dengan kondisi lahan yang relatif datar. Areal budidaya ini pada umumnya berada di lokasi hutan produksi. Kondisi areal hutan produksi ini sudah jarang ditemukan pohon karena sudah dilakukan penebangan sehingga lebihm mudah dialih fungsikan menjadi lahan budidaya perikanan.

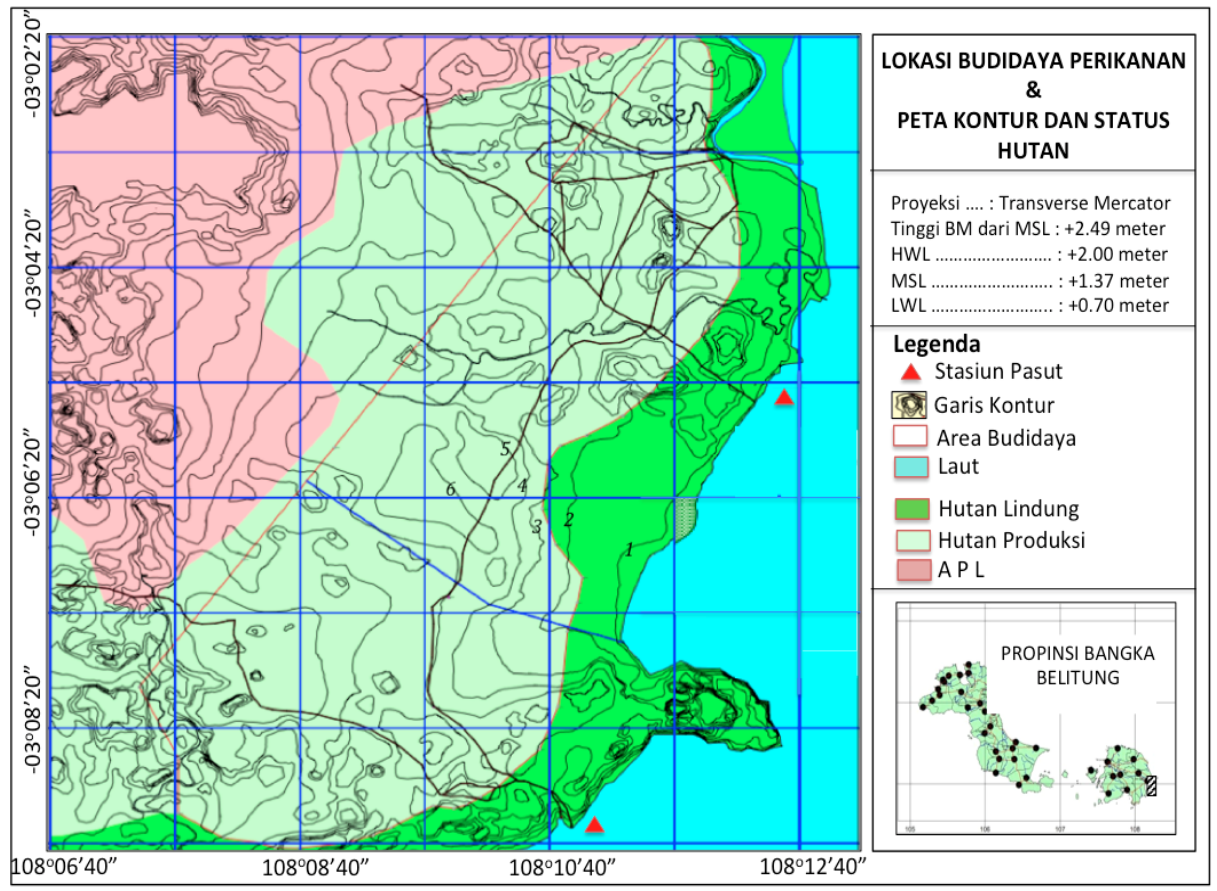

Gambar 7. Peta kontur, satutus lahan dan area potensial untuk budidaya perikanan 
Pada umumnya kondisi mangrove di pinggir pantai timur Belitung masih cukup baik. Kondisi ini harus dipertahankan dengan menetapkan areal di pinggir pantai sebagai hutan lindung. Pada Gambar 7 wilayah mangrove menjadi zona hutan lindung dan tidak bisa dialih fungsikan menjadi lahan budidaya yang berjarak sekitar $1 \mathrm{~km}$ dari garis pantai ke arah lokasi lahan budidaya. Keberadaan mangrove yang masih baik akan menjadi salah satu faktor pendukung keberhasilan budidaya ikan.

\section{KESIMPULAN}

Peta penutupan lahan yang diklasifikasi dari citra satelit dan hasil cek lapangan menunjukkan bahwa di sekitar lokasi yang direncanakan untuk budidaya perikanan terdapat tutupan lahan berupa kelas: hutan primer, hutan sekunder, belukar, rawa/air, lahan terbuka, permukiman, dan galian tambang. Penutupan lahan di lokasi yang potensial untuk budidaya didominasi oleh semak/belukar dan bekas galian tambang.

Peta kontur lahan hasil estimasi dari citra satelit mempunyai pola yang mirip dengan pengukuran terestris dimana ketinggian lahan cenderung meningkat mulai dari pinggir pantai hingga menjauhi pantai. Rata-rata ketinggian hasil estimasi dari citra satelit lebih rendah sekitar $60 \mathrm{~cm}$ dari ketinggian pengukuran terestris. Hasil ini digunakan menjadi acuan untuk koreksi peta topografi yang dihasilkan dari citra satelit.

Tipe pasut di dua lokasi pengukuran di pantai Timur Belitung adalah bertipe tunggal, yaitu dalam satu hari terjadi satu kali pasang dan satu kali surut. Perubahan tinggi muka laut karena pasut di perairan sekitar Gosong Cina berkisar antara $55 \mathrm{~cm}$ hingga 220 $\mathrm{cm}$ dengan rata-rata $134 \mathrm{~cm}$, sedangkan di Batu Putih berkisar antara $45 \mathrm{~cm}$ hingga $212 \mathrm{~cm}$ dengan rata-rata $137 \mathrm{~cm}$.

Berdasarkan peta topografi, tutupan lahan dan data pasang surut, luas wilayah potensial untuk lahan budidaya perikanan di wilayah kajian pantai Belitung Timur adalah sekitar 9.000 ha.

\section{UCAPAN TERIMA KASIH}

Kami mengucapkan terimakasih kepada PT. BIA yang telah memfasilitasi kegiatan penelitian ini sehingga terlaksana. Demikian juga para pembantu survei lapang dan yang membantu pengolahan citra yang tidak dapat kami sebutkan satu persatu kami ucapkan terima kasih.

\section{DAFTAR PUSTAKA}

Berlanga-Robles, C.A. \& A. Ruiz-Luna. (2002). Land use mapping and change detection in the coastal zone of northwest Mexico using remote sensing techniques. Journal of Coastal Research, 514-522.

DKP (Departemen Kelautan dan Perikanan). (2002). Pedoman umum penataan ruang pesisir dan pulaupulau kecil. Depertemen Kelautan dan Perikanan. Jakarta.
Foody, G.M. 2002. Status of land cover classification accuracy assessment. Remote sensing of environment, 80(1), 185-201.

Gorocovich Y. \& A. Voustianiok. (2006). Accuracy assessment of the processed SRTM-base elevation data by CGIAR using filed data from USA and Thailand and its relationship to the terrain characteristics. J. of Remote Sensing and Environmental, 104, 409-415.

Hirano, A., Welch, R. \& H. Lang. (2003). Mapping from ASTER stereo image data: DEM validation and accuracy assessment. ISPRS Journal of Photogrammetry and Remote Sensing, 57(5-6), pp.356-370.

Jhonnerie, R., Siregar, V.P., Nababan, B., Prasetyo, L.B. \& S. Wouthuyzen. (2015). Random forest classification for mangrove land cover mapping using Landsat 5 TM and ALOS PALSAR imageries. Procedia Environmental Sciences, (24): 215-221.

Lagerloef, G.S., Mitchum, G.T., Lukas, R.B., \& P.P. Niiler. (1999). Tropical Pacific near-surface currents estimated from altimeter, wind, and drifter data. Journal of Geophysical Research-Oceans, 104(C10): 23313-23326.

Lumban-Gaol, J., Arhatin, R.E., Manurung, D., \& M. Kawaru. (2007). Pemetaan Sumber Daya Laut Pulau Nias dengan Teknologi Penginderaan Jauh Satelit Pasca-Tsunami 2004. Jurnal Ilmu Pertanian Indonesia, 12(3): 131-140.

Lumban-Gaol, J., Arhatin, R.E. \& M.M. Ling. (2014). Pemetaan Suhu Permukaan Laut Dari Satelit Di Perairan Indonesia Untuk Mendukung "One Map Policy". In Deteksi Parameter Geobiofisik dan Diseminasi Penginderaan Jauh, Prosiding Seminar Nasional Penginderaan Jauh (pp. 433-442).

Manandhar, R., Odeh, I.O., \& T. Ancev. (2009). Improving the accuracy of land use and land cover classification of Landsat data using postclassification enhancement. Remote Sensing, 1(3): 330-344.

Miliaresis, G.C., \& C.V. Paraschou. (2005). Vertical accuracy of the SRTM DTED level 1 of Crete. International Journal of Applied Earth Observation and Geoinformation, 7(1): 49-59.

Singh, S.M. (1994). Effect of surface wind speed and sensor view zenith angle dependence of emissivity on SST retrieval from thermal infrared data: ATSR. International Journal of Remote Sensing, 15(13), pp.2615-2625.

Shalaby, A., \& R. Tateishi. (2007). Remote sensing and GIS for mapping and monitoring land cover and land-use changes in the Northwestern coastal zone of Egypt. Applied Geography, 27(1) 28-41.

Setiawan, I.E., Siregar, V.P., Pramono, G.H. \& D. M. Yuwono. (2014). Pemetaan profil habitat dasar perairan dangkal berdasarkan bentuk topografi: studi kasus Pulau Panggang, Kepulauan Seribu Jakarta. Majalah Ilmiah Globe, 16(2) 125-132. 
Wahidin, N., Siregar, V.P., Nababan, B., Jaya, I. \& S. Wouthuyzen. (2015). Object-based image analysis for coral reef benthic habitat mapping with several classification algorithms. Procedia Environmental Sciences, 24: 222-227. 